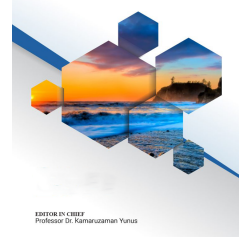

\title{
CHNS ANALYSIS TOWARDS FOOD WASTE IN COMPOSTING
}

\author{
Abdul Rahman Muhammad Firdaus, Mohd Armi Abu Samah*, Khairul Bariyah Abd Hamid, \\ Department of Chemistry, Kulliyyah of Science, International Islamic, University Malaysia, 25200 Kuantan, Pahang, Malaysia \\ *Corresponding author email: marmi@iium.edu.my
}

\section{ARTICLE DETAILS}

\section{Article History:}

Received 12 November 2017 Accepted 12 December 2017 Available online 1 January 2017

\section{Keywords:}

food waste, CHNS, composting, chemical properties, aeration

\section{ABSTRACT}

High food waste generation in Malaysia that reached up to 15, 000 tonnes per day assign for major problems towards environment, economy and social aspect. Alternative method had been studied for the past years, but composting was seen among the best possible solution to treat this matter. Composting not only has an environmentally method but it also produces a valuable end product that will benefit in agricultural sector. Further studies had been done in this paper to represent their macro and micro nutrient quality as well as their bioavailability towards plant and the analysis of data collected in both CHNS analyser and mathematical method using ultimate analysis. This study also applied enhanced composting process with its segregation, drying, grinding and standard aeration time. Each container has been rotated for 5 minutes yet different resting time was applied which are 25, 55, 155 minutes namely A, B, C and D within 2 hours period. Result shown that overall Carbon (C), Nitrogen (N) and Sulphur (S) concentration increases as the higher aeration was applied while the Hydrogen vice versa. The highest elemental percentage distribution recorded is carbon (31\%) while the lowest recorded is S $(0.115 \%)$. The data collected from Ultimate Analysis was seen not applicable to be use as it has the same content as food waste after composting. The compound molecular formula recorded was $\mathrm{C}_{29} \mathrm{H}_{7} \mathrm{~N}_{5} \mathrm{~S}$. Regarding ratio of carbon to nitrogen results, it was found that it ranged from 5.39 to $5.71 \%$ for different compost treatment under study, where the lowest value of $\mathrm{C}$ and $\mathrm{N}$ ratio (5.39\%) for sample $\mathrm{C}$ and the highest value $(5.71 \%)$ was obtained for sample B with all has the same $\mathrm{C} / \mathrm{N}$ ratio which is $6: 1$ which suitable range in application of soil amendment. Therefore, this study found a significant relationship between chemical factors and compost formation which contribute to better analysis, especially to food waste management.

\section{INTRODUCTION}

Ecological diversity on earth make balanced system in which organic waste has been produced and recycled at the same time as such some organisms use it as their source of nutrient and energy where with this it can be seen that recycling organic waste act as functional integration towards any ecosystem. The process of natural degradation in organic waste happen with the ability of organisms to recycle organic waste known as composting, as humans utilize the process for their benefits, they started to see the process can be precisely control in order to perform an efficient process that produce high quality compost. Composting can be considered as a low-cost biological decomposition processes where it is circuited by microbial activity but with consideration of the physicalchemical parameter such as temperature, aeration, MC, carbon/nitrogen $(\mathrm{C} / \mathrm{N})$ ratio and $\mathrm{pH}[1]$.

Currently, substantial research efforts have been carried out to evaluate the impacts of various parameters on composting performance and microbial community composition. The state-of-the-art environmental assessment of waste management systems has relied on the data for the physicochemical composition of individual material fractions comprising the specific waste [2]. According to a study state that carbon formation related with decomposition of organic substrates whereby if in the presence of oxygen, it is known as aerobic composting [3]. Optimum composting process occur through range of $\mathrm{C} / \mathrm{N}$ ratio of 30 to 40 , and the $\mathrm{MC}$ between $50 \%$ and $65 \%$ but later several studies found that $\mathrm{C} / \mathrm{N}$ ratio lower than 20 can also be effective for composting process [4,5].

Moreover, several studies also laid out the effect of adding bulking agents in which to adjust the MC, N-content, $\mathrm{C} / \mathrm{N}$ ratio, and void spaces between particles in the past, since most waste materials such as sewage sludge, food waste and animal manure have too low $\mathrm{C} / \mathrm{N}$ ratios and too high $\mathrm{MC}$ for efficient composting [6-9]. Generally, modification of physical properties of composting feed-stock may resulted from different bulking agents as well as change the biodegradation kinetics and composting performance $[7,8,10]$. Thus, it is a prerequisite for collection program managers to have detail information about the nature and quantity of solid waste generated in order to set appropriate management systems which in this paper will be focused on composting. The two most significant issues in a compost process, strictly linked, are original matrix physicochemical composition and existing microorganism populations. Performance of composting correlates with proper decision on their controlling parameter whether correspond to physical and chemical properties of organic wastes in order to control in situ processes to be identifiable and reliable for management [11].

In addition, composting acts as an alternative solid waste management system (SWM) where the organic matters can be recycling into beneficial products. Although composting has its own benefits, however, the production of practical common organic compost required a lot of time. In Malaysia, common issue such as scarcity of information where out-dated data were used by most researchers and government officials for the estimation of future trends in regard to the solid waste compositions [12]. However, the optimization of formula in composting process was convenient in order to perform efficient process as well as high quality of composting other than encountering the slow composting process.

Hence, this study hypothesises that High frequency of stirring cause more introduction of oxygen towards compost pile significantly provide more resources for bacteria degradation in organic waste which consequently produce better chemical quality of compost which contain micro and macro nutrient. The overall aim of the research is to identify of compost quality in based on its major chemical composition (C, H, N, S).

\section{MATERIALS AND METHODS}

\subsection{Equipment}

Equipment and apparatus used in this study are listed in Table 1 
Table 1: List of Equipment

\begin{tabular}{cc}
\hline Apparatus and Equipment & Company \\
\hline Analytical Balance Digital Scale & Perkin Elmer \\
pH Reader & Mettler Toledo \\
CHNS Analyzer & Elementar \\
710- $\boldsymbol{\mu m}$ Mesh Stainless Steel Sieve & Endescott \\
Sieve Shaker EFL 2000 & Endescott \\
Apparatus and Equipment & Company \\
Analytical Balance Digital Scale & Perkin Elmer \\
\hline
\end{tabular}

\subsection{Introduction}

The initial levels of the physical parameters in food waste can be altered in order to create waste mixtures that biodegrade at higher rates. The study is both field based experiment and laboratory based experiment as indicated in Figure 2. The experiment was conducted for achieving the two objectives of the project which are (i) optimization of Pre-Composting Process for food waste and (iii) identification of major element in its chemical composition ( $\mathrm{C}, \mathrm{H}, \mathrm{N}, \mathrm{S}$ ) using CHNS Analyzer.

\subsection{Model Research Framework}

The overall model research framework as shown in Figure 1 was created for this project. The food waste was collected from Ana Ikan Bakar Petai Restaurant, Tanjung Lumpur, Kuantan, Pahang, Malaysia coordinated at $3^{\circ} 47^{\prime} 52.17^{\prime \prime} \mathrm{N} ; 103^{\circ} 20^{\prime} 23.441^{\prime \prime} \mathrm{E}$ as shown in figure 1 .

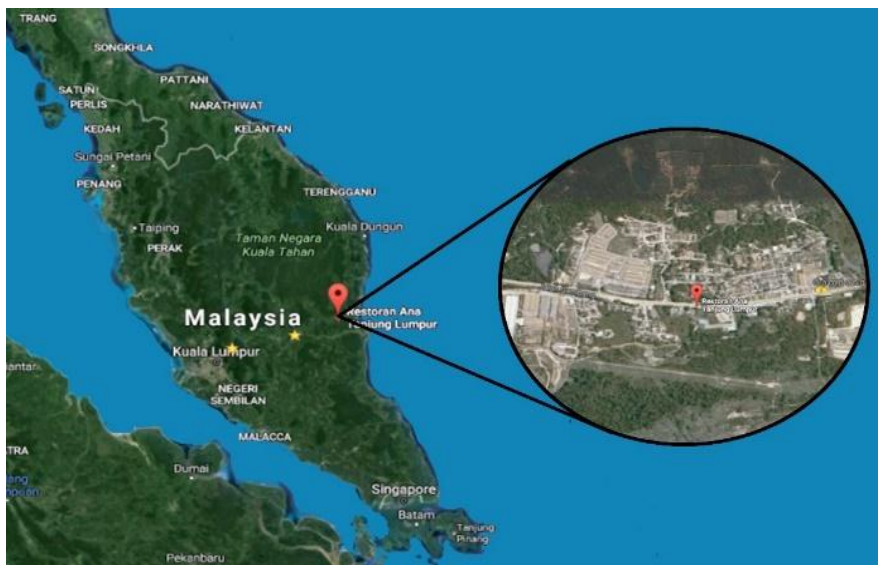

Figure 1: Location of the sampling sites in Tanjung Lumpur (Source: GoogleMaps, 2017)

In this project, the food waste consists of kitchen waste use for cooking due to overproduction, spoilage, expiration, and trim waste and postconsumer FW which consist table scrap food refuse due to behaviors, portion sizes, self-service was grinded and then dried before further divided into $5 \mathrm{~kg}$ in each composting bin whereby the waste had been stirred for 5 minutes within different frequency per hour. The time used to stir the food waste is the aeration time whereby the balanced nonaerated time is the resting time. The resting time was set differently within the sample which are 25, 55 and 115 minutes. The result collected had shown the value of temperature, $\mathrm{pH}$, and $\mathrm{MC}$ in hourly basis. The physicochemical properties of the sample such as $\mathrm{pH}$, temperature, hydrogen ion level, MC, the percentage of the major elements which are Carbon (C), Nitrogen (N), Hydrogen (H), Oxygen (O) and Sulphur (S), level of heavy metals (Magnesium (M), Potassium (K), Calcium (Ca), Manganese $(\mathrm{Mn})$, Copper ( $\mathrm{Cu})$, Zinc $(\mathrm{Zn})$, Phosphorus (P)) and energy content had been further analysed through statistical model analysis and machinated based analysis. In this paper only the analysis of major elements was studied and displayed.

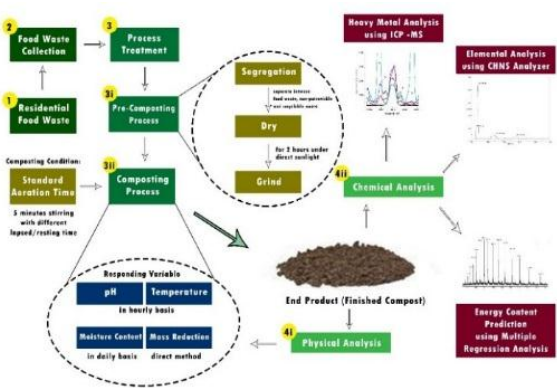

Figure 2: Model Quick-Composting Research Framework
2.4. Estimation of the Percentage of Element (E\%) by Ultimate Analysis and CHNS Analyzer

The ultimate analysis was used to determine the elemental composition of the food waste including ash, carbon, hydrogen, nitrogen, sulphur, and oxygen. Ultimate analysis determined each element through chemical analysis and expressed it as percentage of the total mass of the original sample.

Table 2: Typical data on ultimate analysis of the components in residential Food Waste $[13,14]$.

\begin{tabular}{|c|c|c|c|c|c|c|}
\hline & \multicolumn{6}{|c|}{ Percent by weight (dry basis) } \\
\hline $\begin{array}{l}\text { Component } \\
\text { Food waste }\end{array}$ & $\begin{array}{c}\text { Carbon } \\
48.0\end{array}$ & $\begin{array}{c}\text { Hydrogen } \\
6.4\end{array}$ & $\begin{array}{c}\text { Oxygen } \\
37.6\end{array}$ & $\begin{array}{c}\text { Nitrogen } \\
2.6\end{array}$ & $\begin{array}{c}\text { Sulfur } \\
0.4\end{array}$ & $\begin{array}{l}\text { Ash } \\
5.0\end{array}$ \\
\hline
\end{tabular}

According to a group researcher, the ultimate analysis with $\mathrm{H}(\%)$ represents the element composition in a sample by percent had been based by using $\mathrm{H}[13,14]$. (4) with the aids of the Table 2 for data reference composition in 100gram sample. The procedure for deriving chemical formula is given in following: (i) ultimate analysis and moisture of FW was identified, (ii) the MC was converted into Hydrogen and Oxygen, (iii) the composition was revised in $\mathrm{kg}$ (iv) molar composition of $\mathrm{FW}$ was computed, (iv) further normalized molar ratio was computed for chemical formula of FW formed. Furthermore, the elemental composition was analysed by using CHNS Analyzer Vario Macro Cube.

\section{RESULTS AND FINDINGS}

\subsection{Introduction (Scope of Data)}

Successful composting requires a balance between several key parameters. The greatest cause for failure in composting operations was the door, due to improper operation. Foul odours can cause issues with neighbours; they are also an indicator of improper treatment. Other composting failures can include failure to deactivate pathogenic microorganisms. By maintaining proper operating parameters, odours are contained, and composting success is assured. The characterization of food waste can be categorizes based on their feedstock and region: the feedstock such as animal-derived food waste, general food waste and plant food waste whereby site sources are commercial, residential and agricultural. In this study, the food waste categorizes general residential food waste. Knowledge of waste generation and composition is useful for facilitating the preparation of an effective and economical long-term plan for waste management. Waste generation data and waste composition data will determine the potency of waste for composting.

\subsection{Enhanced Pre-Composting Process}

The enhanced composting process was achieved in 3 days which is much quicker than the recent composting process study in literature (as stated in the section 2.9.3). The compost was form in 3 days' times shown that the physical structure plays crucial role here. When FW is shredded, nutrient accessibility to microbes increases due to increased surface/volume ratio; therefore, degradation accelerates and all the easily biodegradable substrate (OM) is depleted [15].

\subsection{Identification of Major Element in Its Chemical Composition (C,} $\mathrm{H}, \mathbf{N}, \mathbf{S}$ )

The major element composition and concentration of heavy metal properties of the sample were determined by the chemical properties based on two type of sample which is the initial sample and final sample (after finish compost). The data were analyzed through calculation and computerized software set-up in CHNS Analyzer and ICP-MS in which to determine if the addition of aeration time in an hour of composting process significantly influenced the major element composition $(\mathrm{C}, \mathrm{H}, \mathrm{N}$ and S) and concentration of heavy metals from each of the initial and final sample from the overall sample. Meanwhile, data of identification of the major chemical element in the sample using ultimate analysis were estimated based on the data from the final compost data only. After composting, there was significant difference in major element composition and concentration of heavy metal properties of the sample in compost temperatures was observed between the different compost treatments.

3.4. Identification of Major Element in Its Chemical Composition (C, $\mathrm{H}, \mathrm{N}, \mathrm{S}$ )

The major element composition and concentration of heavy metal 
properties of the sample were determined by the chemical properties based on two type of sample which is the initial sample and final sample (after finish compost).

The data were analyzed through calculation and computerized software set-up in CHNS Analyzer and ICP-MS in which to determine if the addition of aeration time in an hour of composting process significantly influenced the major element composition (C, H, N and S) and concentration of heavy metals from each of the initial and final sample from the overall sample. Meanwhile, data of identification of the major chemical element in the sample using ultimate analysis were estimated based on the data from the final compost data only. After composting, there was significant difference in major element composition and concentration of heavy metal properties of the sample in compost temperatures was observed between the different compost treatments.

\subsection{Estimation of The Percentage of Element by Ultimate Analysis and CHNS Analyzer}

The highest elemental percentage distribution recorded is carbon with $48 \%$ while the lowest recorded is Sulphur $0.4 \%$. The compound molecular formula is C320H5080184N15S through mole ratio data calculated. The highest content (\%) of all elements (C, H, N, S, O, and Ash) was Sample C. Moreover, the estimated data that was calculated had shown approximately similar result from all samples. For sulphur content, compost from Sample A contained $0.2 \%$ less total sulphur compared to Sample B and C. For hydrogen content, compost from Sample A contained less $3.2 \%$ total hydrogen compared to Sample $\mathrm{C}$ where it is less $2.5 \%$ from Sample B. For oxygen content, compost from Sample A contained 18.8\% less total oxygen compared to Sample C where it is less $15.1 \%$ from Sample B. For oxygen content, compost from Sample. A contained $18.8 \%$ less total oxygen compared to Sample C where it is less $15.1 \%$ from Sample B. For ash content, compost from Sample A contained $2.5 \%$ less total ash compared to Sample C where it is less $2 \%$ from Sample B. For carbon content, compost from Sample A contained $24 \%$ less total carbon compared to Sample C where it is less 19.2\% from Sample B. For nitrogen content, compost from Sample A contained 1.3\% less total nitrogen compared to Sample C where it is less $1 \%$ from Sample B.

Therefore, the reduction of aeration of time per hour of composting process created an increase in the major nutrients which are the total sulphur increased $0.2 \%$, the hydrogen increased $3.2 \%$, the oxygen increased $18.8 \%$, the nitrogen increased, and carbon increased $24 \%$. The ratio of $\mathrm{C}$ to $\mathrm{N}$ is between 1: 18 as shown in Figure 3.

Percentage Distribution Element in Overall Sample (\%)

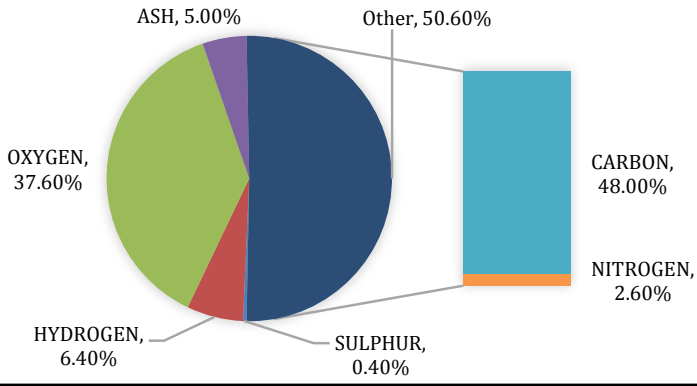

Figure 3: Percentage Distribution Element in Overall Sample (\%) using Ultimate Analysis

Table 3: Typical data in Elemental Analysis (Tchobanuclous, (1990); Pitchel, (2005))

\begin{tabular}{ccccccc}
\hline Type & C & H & O & N & S & Ash \\
\hline Mixed food & 73.0 & 11.5 & 14.8 & 0.4 & 0.1 & 0.2 \\
\hline
\end{tabular}

The typical data in Elemental Analysis based on the references shown in Table 3 that elemental contents are higher than the data in the sample. For chemical composition in the sample, result in Figure 3 shows that the $\mathrm{C} / \mathrm{N}$ ratio for the sample is 1 : 18 , this indicated that compost produced can supply for essential nutrient towards plant soil.

These results are in agreement with the results obtained whose found that the desirable $\mathrm{C} / \mathrm{N}$ ratio ranged for ready-to-use compost from 15:1 to 20:1 and it also agreed with the result obtained by a group researcher whose found that range of $\mathrm{C} / \mathrm{N}$ ratio for kitchen waste is $13-18: 1[16,17]$. This also shows that aeration does not play an important role in the elemental percentage of the sample in overall compost as the tendency to rapid decomposition and continuously decrease the volume and aeration depend on high ratio of $\mathrm{C} / \mathrm{N}$.

\subsection{Elemental Analysis Using CHNS Analyzer}

Total data recorded analysis through CHNS analyser of food waste was shown in Table 4 . Table 4 presented all the $\mathrm{C} / \mathrm{N}$ ratio in the sample before and after finish sampling. The highest elemental percentage distribution recorded is carbon with $31 \%$ while the lowest recorded is Sulphur $0.115 \%$. The compound molecular formula is C29H7N5S through mole ratio data calculated.

The highest content (\%) of element $(\mathrm{C}, \mathrm{H}, \mathrm{N}, \mathrm{S})$ was varied between all samples as shown in figure 4 . All elemental composition $\mathrm{C}, \mathrm{N}$ and $\mathrm{S}$ was shown increasing trend throughout the composting process for all sample except hydrogen. Regarding ratio of carbon to nitrogen results, it was found that it ranged from 5.39 to $5.71 \%$ for different compost treatment under study, where the lowest value of $\mathrm{C}$ and $\mathrm{N}$ ratio $(5.39 \%)$ for sample $\mathrm{C}$ and the highest value $(5.71 \%)$ was obtained for sample B with all has the same $\mathrm{C} / \mathrm{N}$ ratio which is $6: 1$.

These results are in agreement with for organic was found that it ranged. In comparison with elemental composition in composted food waste, sulphur content from Sample A contained 0.021\% less total sulphur compared to Sample B and less $0.015 \%$ than C. For hydrogen content compost from Sample A contained more $0.14 \%$ total hydrogen compared to Sample C and more $0.09 \%$ from Sample B. For oxygen content, compost from Sample A contained $18.8 \%$ less total oxygen compared to Sample C where it is less $15.1 \%$ from Sample B. For carbon content, compost from Sample A contained $0.8 \%$ more total carbon compared to Sample C where it is less $1.2 \%$ from Sample B. For nitrogen content, compost from Sample A contained $0.13 \%$ less total nitrogen compared to Sample C where it is less $0.16 \%$ from Sample B. As for oxygen content, the values could not be identified due to lack of appropriate spare parts within CHNS Analyzer. Therefore, the reduction of aeration of time per hour of composting process created an approximate increase and decrease in the major nutrients which are the total sulphur increased $0.09 \%$, the hydrogen decreased $1.80 \%$, the nitrogen increased $1.02 \%$ and carbon increased $12.91 \%$.

Other than that, the carbon contents in final products increase significantly but nitrogen content changes a little resulting in higher $\mathrm{C} / \mathrm{N}$ ratios. The similar phenomenon was also found in the previous studies using the same composter [18-23]. It was due to the sufficient air supply and frequent agitation of the composter. Effects of compositions on food waste composting. The end ratio of $\mathrm{C}$ to $\mathrm{N}$ of all sample for $\mathrm{T} 72$ is arround $6: 1$. Table 4.2 showed that there is the increase in the $\mathrm{C} / \mathrm{N}$ ratio $(4: 1$ to $6: 1)$. A total range of $\mathrm{C} / \mathrm{N}$ ratio increment was around $25.6-31.2 \%$. This indicates that there is degradation of the substrate and the stabilization of compost also occurred. These parameters are within the range required for agricultural use as soil amendment agreed as [24-27]. The data above showed significant indicator that the product of food waste compost gain from this study is not at an optimum level compare to use of standard compost as fertilizer which is 23: 1 (Kim et al., 2008) [14].

Table 4: Carbon/Nitrogen Ratio in all sample and their average for T72 (\%)

\begin{tabular}{ccc}
\hline TIME (DAY) & $\mathbf{C} / \mathbf{N}$ & C: $\mathbf{N}$ \\
\hline $\mathbf{T}_{\mathbf{0}}$ & 3.94 & $4: 1$ \\
$\mathbf{T}_{72} \mathbf{A}$ & 5.67 & $6: 1$ \\
$\mathbf{T}_{72} \mathbf{B}$ & 5.71 & $6: 1$ \\
$\mathbf{T}_{72} \mathbf{C}$ & 5.39 & $6: 1$ \\
$\mathbf{T}_{72}$ Average & 5.59 & $6: 1$
\end{tabular}

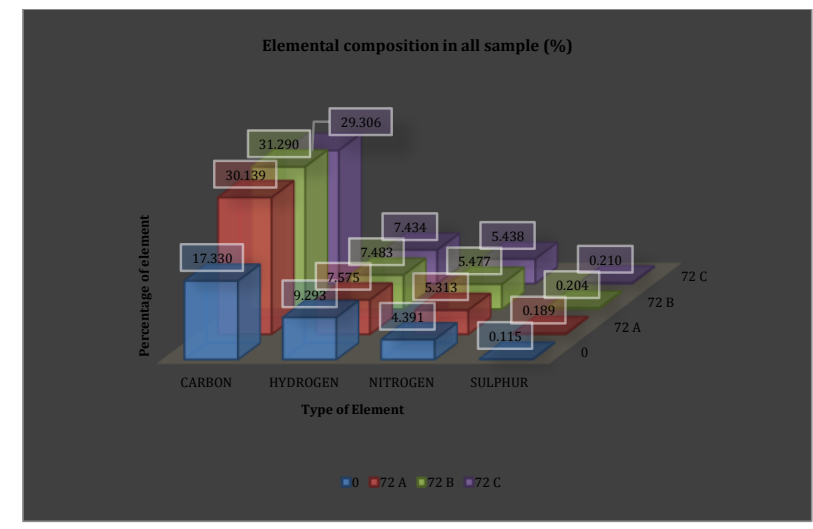

Figure 4: Comparison of Elemental (C, H, N And S) Percentage Distribution 
in Sample (\%)

\subsubsection{Comparison Between Ultimate Anaysis And CHNS Analyzer}

Based on Table 3 in comparison with Table 4, the combined data was formed into the Table 5 below whereby the data of food waste composition also included in which significant differences were seen between both methods [28]. The literature also stated that only $1 \%$ of $\mathrm{C}, \mathrm{H}, \mathrm{S}$ and $\mathrm{O}$ were based on mass balance calculation whereby $61 \%$ of data were obtained using direct chemical analysis [28].

The CHNS analyzer uses multi-element isotope analysis information for characterization whereby they imply conversion of organic sample into simple gases and mass spectrometric on the isotopologues of the product gas molecules will be determined [29].

Other studies also supported that Elementar (Hanau, Germany) suitable for simultaneous isotope ratio determination of nitrogen, carbon and sulphur isotopes in a single run whereby it major advantages is capability of combusting up to $100 \mathrm{mg}$ of organic samples which provide large provision of sufficient amount of SO2 for isotope analysis even from material with low sulphur content [29-38]. Moreover, the separation of combustion gases as their second characteristic is performed by reversible adsorption on (molecular sieve) traps in which they allocated to a specific gas species.

Table 5: Comparison of Carbon, Hydrogen, Oxygen, Nitrogen, Sulphur and Ash Compositions, \% (in average) in sample using different method for T72 (\%) follow Ramona et al. (2016)

\begin{tabular}{lcccccc}
\hline SOURCE & METHOD & CARBON & HYDROGEN & NITROGEN & $\begin{array}{c}\text { SULPHU } \\
\mathbf{R}\end{array}$ & C: \\
\hline $\begin{array}{l}\text { COMPOSTE } \\
\text { D FOOD }\end{array}$ & $\begin{array}{c}\text { ULTIMATE } \\
\text { ANALYSIS }\end{array}$ & 48.0 & 6.4 & 2.6 & 0.4 & $18: 1$ \\
$\begin{array}{l}\text { WASTE } \\
\text { FOOD }\end{array}$ & CHNS & 30.2 & 7.5 & 5.4 & 0.2 & $6: 1$ \\
WASTEa & ANALYZER & 47.9 & 6.5 & 3.0 & 0.378 & $16: 1$ \\
\hline
\end{tabular}

\section{CONCLUSION}

In this study, the CHNS concentrations were monitored before and after composting process. Different set of aeration time within the duration of 2 hours was applied towards food waste during composting process in order to evaluate their effect and interactions upon the CHNS concentration. In general, aerated composting provides higher CHS as more aeration was applied except hydrogen act vice versa. The data collected from Ultimate Analysis was seen not applicable to be used as it had the same content as food waste after composting. However, $\mathrm{C} / \mathrm{N}$ ratio which is 6: 1 is suitable range in application of soil amendment. Therefore, this study gives positive result on its application to the related agencies, the public and the industrial player to use the compost in order to counter this major environmental threat. This study found a significant relationship between chemical factors and compost formation which contribute to better analysis, especially to food waste management.

\section{ACKNOWLEDGEMENT}

The authors fully acknowledged Ministry of Higher Education (MOHE) and to all team researchers for this study until successfully.

\section{REFERENCES}

[1] Fathi, H., A Zangane, A. H., Moradi, H. 2014. Municipal solid waste characterization and it is assessment for potential compost production: A Case Study in Zanjan City, Iran, American Journal of Agriculture and Forestry, 2 (2), 39-44.

[2] Edjabou, M. E., Jensen, M. B., Gotze, R., Pivnenko, K., Peterson, C., Scheutz, C., Astrup, T. F. 2015. Municipal solid waste composition: Sampling methodology, statistical analysis, and case study evaluation. Waste Management, 36, 12-23.

[3] Haug, R. T. 1993. The Practical Handbook of Compost Engineering, Lewis Publishers, Boca Raton, USA.

[4] Agnew, J. M., Leanard, J. J. 2003. The physical properties of compost. Compost Science and Utilization, 11 (3), 238-264.

[5] Zhu, N. 2007. Effect of low initial C/N ratio on aerobic composting of swine manure with rice straw. Bioresource Technology, 98 (1), 9-13.
[6] Gea, T., Barrena, R., Artola, A., Sanchez, A. 2007. Optimal bulking agent particle size and usage for heat retention and disinfection in domestic wastewater sludge composting. Waste Management, 27 (9), 1108-1116.

[7] Kim, J. D., Park, J. S., In, B. H., Kim, D., Namkoong, W. 2008. Evaluation of pilot-scale in-vessel composting for food waste treatment. Journal of Hazardous Material, 154 (1-3), 272-277.

[8] Adhikari, B. K., Barrington, S., Martinez, J., King, S. 2009. Effectiveness of three bulking agents for food waste composting. Waste Management, 29 (1), 197-203.

[9] Iqbal, M. K., Shafiq, T., Ahmed, K. 2010. Characterization of bulking agents and its effect on physical properties of compost. Bioresource Technology, 101 (6), 1913-1919.

[10] Yanez, R., Alonso, J. L., Diaz, M. J. 2009. Influence of bulking agent on sewage sludge composting process. Bioresource Technology, 100 (23), 5827-5833.

[11] Huerta-Pujol, O., Soliva, M., Martinez-Farre, F. Xavier, Valero, J., Lopez, M. 2010. Bulk density determination as a simple and complementary tool in composting process control. Bioresource Technology, 101 (3), 995-1001.

[12] Johari A., S. I. 2012. Economic and environmental benefits of landfill gas from municipal solid waste in Malaysia. Renewable and Sustainable Energy Reviews, 16 (5), 2907-2912.

[13] Tchobanoglous, G. 1993. Integrated solid waste management engineering principles and management issues. McGraw-Hill series in water resources and environmental engineering. New York. McGraw-Hill. 1993. xxi, 978 p. $23 \mathrm{~cm}$.

[14] Pitchel, J. 2005. Waste Management Practices: Municipal, Hazardous and Industrial. CRC Press, Taylor and Francis Group. [This book provides a comprehensive and detailed review of municipal, hazardous and industrial waste in the United States.]

[15] Hamid, A., Ahmad, A., Ibrahim, M. H., Rahman, N. A. 2012. Food Waste Management in Malaysia-Current situation and future management options. Journal of Industrial Research and Technology, 2 (1), 36-39.

[16] Al Ansari, M. S. 2012. Improving Solid Waste Management in Gulf Cooperation Council States: Developing Integrated Plans to Achieve Reduction in Greenhouse Gases. Modern Applied Science, 60-68.

[17] Aranda, V., Macci, C., Peruzzi, E., Masciandaro, G. 2015. Biochemical activity and chemical-structural properties of soil organic matter after 17 years of amendments with olive-mill pomace co-compost. Journal of environmental management, 147, 278-285.

[18] Badgie, D. S. 2012. Assessment of Municipal Solid Waste Composition in Malaysia: Mangement, Practice, and Challenges. Polish Journal of Environmental Study, 539-547.

[19] Balestrasse, K. B., Tomaro, M. L., Batlle, A., Noriega, G. O. 2010. The role of 5 -aminolevulinic acid in the response to cold stress in soybean plants. Phytochemistry, 71 (17), 2038-2045.

[20] Bhattarai, R., Kalita, P.K., Yatsu, S., Howard, H.R., Svendsen, N.G. 2011. Evaluation of compost blankets for erosion control from disturbed lands. Journal of Environmental Management, 92, 803-812.

[21] Fauziah, S. H., Agamuthu, P. 2012. Trends in sustainable landfilling in Malaysia, a developing country. Waste Management and Research, 1-8.

[22] Food and Agriculture Organization (FAO). 2012. Towards the future we want: End hunger and make the transition to sustainable agricultural and food systems. Food and agriculture organization of the United Nations Rome.

[23] Gustafsson, U., Wills, W., Draper, A. 2011. Food and public health: Contemporary issues and future directions. Critical Public Health, 21 (4), 385-393

[24] Ismail, S. N. S., Manaf, L. A. 2013. The challenge of future landfill: A case study of Malaysia. Journal of Toxicology and Environmental Health Sciences, 5 (6), 86-96. 
[25] Johari A., H. A. 2014. Municipal Solid Waste Management and Potential Revenue from Recycling in Malaysia. Modern Applied Science, 8 (4), 37-49. doi:10.5539/mas. v8n4p37

[26] JPSPN. 2013. National Solid Waste Management Department. Ministry of Human Well-being, Housing and Local Government. Retrieved from JPSPN: http:// www.kpkt.gov.my/jpspn_en_2013/main.php? Content $=$ articles $\&$ ArticleID $=43 \&$ IID

[27] Guerrero, L. A., Maas, G., Hogland, W. 2013. Solid waste management challenges for cities in developing countries. Waste Management, 33 (1), $220-232$

[28] Manaf, L.A., Samah, M.A.A., Zukki, N.I.M. 2009. Municipal solid waste management in Malaysia: Practices and challenges. Waste Management, 29 (11), 2902-2906.

[29] Levis, J. W., Barlaz, M. A., Themelis, N. J., Ulloa, P. 2010. Assessment of the state of food waste treatment in the United States and Canada. Waste Management, 30 (8), 1486-1494.

[30] Rawat, M., Ramanathan, A.L., Kuriakose, T. 2013. Characteristics of Municipal Solid Waste Compost (MSWC) from selected Indian cities - a case study for its sustainable utilisation. Journal of Environmental Protection, 4, 163-171.

[31] Melikoglu, M., Lin, C.S.K., Webb, C. 2013. Analysing global food waste problem: pinpointing the facts and estimating the energy content. Central European Journal of Engineering, 3 (2), 157-164.
[32] Oakdene Hollins, R. H. 2013. Overview of Waste in the UK Hospitality and Food Service Sector. Brussels: Wrap and Resources Action Programme Technical Report.

[33] R Couth, C. T. 2010. Carbon emissions reduction strategies in Africa from improved waste management: A review. Waste Management, 30 (11), 2336-2346.

[34] Saheri, S., $\quad$ Mir, M.A., Basri, N.E.A., Begum, R.A., Mahmood, N.Z. 2009. Solid Waste Management by considering the composting potential in Malaysia toward a green country. e-BANGI, 4 (2), 48-55.

[35] Samah, M. A. A., Manaf, L. A., Ahsan, A., Sulaiman, W. N. A., Agamuthu, P., D'Silva, J. L. 2013. Household Solid Waste Composition in Balakong City, Malaysia: Trend and Management. Polish Journal of Environmental Studies, 22 (6), 01-20.

[36] SWCorp Malaysia. 2016. Official Website of SWCorp. Solid Waste and Public Cleansing Management Corporation. Available from: http://www.swcorp.my/index.php/en/ 22 June 2017]

[37] Uiterkamp, B.J.S., Azadi, H., Ho, P. 2011. Sustainable recycling model: A comparative analysis between India and Tanzania. Resources, Conservation and Recycling, 55 (3), 344-355.

[38] Zhang, Z., Li, M., Chen, W., Zhu, S., Liu, N., Zhu, L. 2010. Immobilization of lead and cadmium from aqueous solution and contaminated sediment using Nano-hydroxyapatite. Environmental Pollution, 158, 514-519. 